\title{
Intracellular pH-Induced Tip-to-Tip Assembly of Gold Nanorods for Enhanced Plasmonic Photothermal Therapy
}

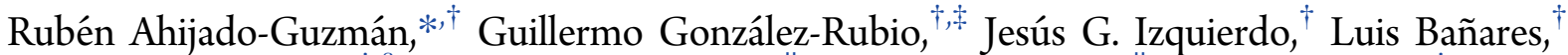 \\ Iván López-Montero, ${ }^{\dagger} \S$ Alicia Calzado-Martín," Montserrat Calleja," Gloria Tardajos, ${ }^{\dagger}$ \\ and Andrés Guerrero-Martínez ${ }^{*} \dagger$ \\ ${ }^{\dagger}$ Departamento de Química Física I, Universidad Complutense de Madrid, Avda. Complutense s/n, 28040 Madrid, Spain \\ ${ }^{\ddagger}$ BioNanoPlasmonics Laboratory, CIC biomaGUNE, Paseo de Miramon 182, 20009 Donostia/San Sebastián, Spain \\ ${ }^{\S}$ Instituto de Investigación Hospital 12 de Octubre i+12, Avda. de Córdoba s/n, 28041 Madrid, Spain \\ "Instituto de Microelectrónica de Madrid (IMM, CSIC) Isaac Newton 8, Tres Cantos, 28760 Madrid, Spain
}

Supporting Information

\begin{abstract}
The search for efficient plasmonic photothermal therapies using nonharmful pulse laser irradiation at the near-infrared (NIR) is fundamental for biomedical cancer research. Therefore, the development of novel assembled plasmonic gold nanostructures with the aim of reducing the applied laser power density to a minimum through hot-spot-mediated cell photothermolysis is an ongoing challenge. We demonstrate that gold nanorods (Au NRs) functionalized at their tips with a $\mathrm{pH}$-sensitive ligand assemble into oligomers within cell lysosomes through hydrogen-bonding attractive interactions. The unique intracellular features of the plasmonic oligomers allow us to significantly reduce the femtosecond laser power density and $\mathrm{Au} \mathrm{NR}$ dose while still achieving excellent cell killing rates. The formation of gold tip-to-tip oligomers with longitudinal localized surface plasmon resonance bands at the NIR, obtained from low-aspect-ratio Au NRs close in resonance with $800 \mathrm{~nm}$ Ti:sapphire $90 \mathrm{fs}$ laser pulses, was found to be the key parameter for realizing the enhanced plasmonic photothermal therapy.
\end{abstract}

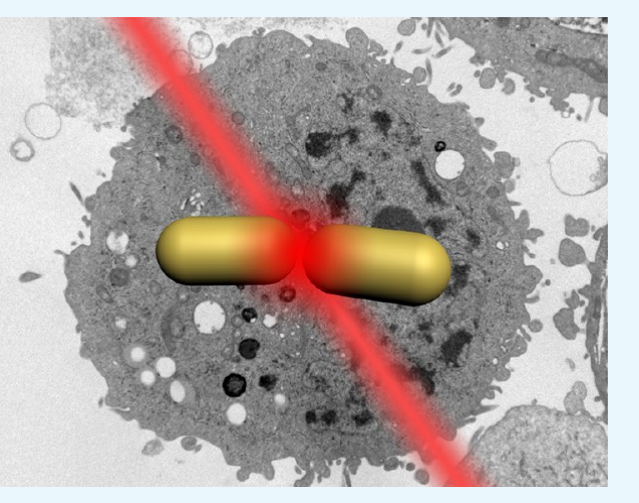

\section{INTRODUCTION}

The use of plasmonic gold nanoparticles (Au NPs) for biomedical purposes has considerably increased in the last few years owing to their singular optical properties and high biocompatibility. ${ }^{1}$ In this context, gold nanorods (Au NRs) are attracting special attention due to the strong light scattering and absorption at their longitudinal localized surface plasmon resonance (L-LSPR) wavelength compared to those of spherical Au NPs. ${ }^{2,3}$ Moreover, depending on the aspect ratio, the L-LSPR band of Au NRs can be readily tuned to the infrared region of the electromagnetic spectrum, ${ }^{4}$ which corresponds to the optical window of biological tissues $(650-1000 \mathrm{~nm}){ }^{5}$ These optical features make Au NRs singularly suitable for in vitro and in vivo medical applications, ${ }^{6}$ for instance, as tools for plasmonic photothermal therapy (PPTT). ${ }^{1,7}$

PPTT utilizes Au NPs to convert nonharmful light into thermal energy through the interaction of laser radiation with the LSPR of plasmonic nanostructures. ${ }^{8}$ The intracellular Au NP heating achieved with PPTT has shown great potential for killing cancer cells by apoptosis ${ }^{9}$ or photothermolysis ${ }^{7}$ processes. With regard to the morphology of the nanocrystals, the use of anisotropic Au NPs, such as hollow nanocages ${ }^{10}$ or nanoprisms, ${ }^{9}$ to efficiently induce cell death is a notable example of the potential application of such systems in cancer treatment. Additionally, Au NRs have been successfully employed in the PPTT-mediated inhibition of tumor growth through the targeting ability of stem cells. ${ }^{11}$ With regard to the laser source, under continuous wave $(\mathrm{CW})$ laser irradiation, the overall effect of mild thermal heating on Au NPs is intense enough to induce the apoptosis of cancer cells. ${ }^{9,12}$ Complementary to $\mathrm{CW}$ sources, ${ }^{13}$ pulsed lasers enable irradiation with low intensity over ultrashort periods of time, allowing PPTT through highly localized heating of intracellular Au NPs. ${ }^{10}$ As a remarkable example, irradiation of plasmonic $\mathrm{Au}$ nanostars with a near-infrared (NIR) femtosecond (fs) laser at a power density of $0.2 \mathrm{~W} / \mathrm{cm}^{2}$, below the maximum permissible exposure (MPE) threshold of skin $\left(0.4 \mathrm{~W} / \mathrm{cm}^{2}\right.$ at $\left.850 \mathrm{~nm}\right),{ }^{14}$ has been used for the effective photothermolysis of breast cancer cells. ${ }^{15}$

Controlled Au NP ensembles are able to confine light in their interparticle gaps, ${ }^{16}$ giving rise to electromagnetic field enhancements that are several orders of magnitude higher than those of the incident field, known as hot spots. ${ }^{17}$ Because of the associated photothermal enhancement at such

Received: August 10, 2016

Accepted: September 6, 2016

Published: September 16, 2016 

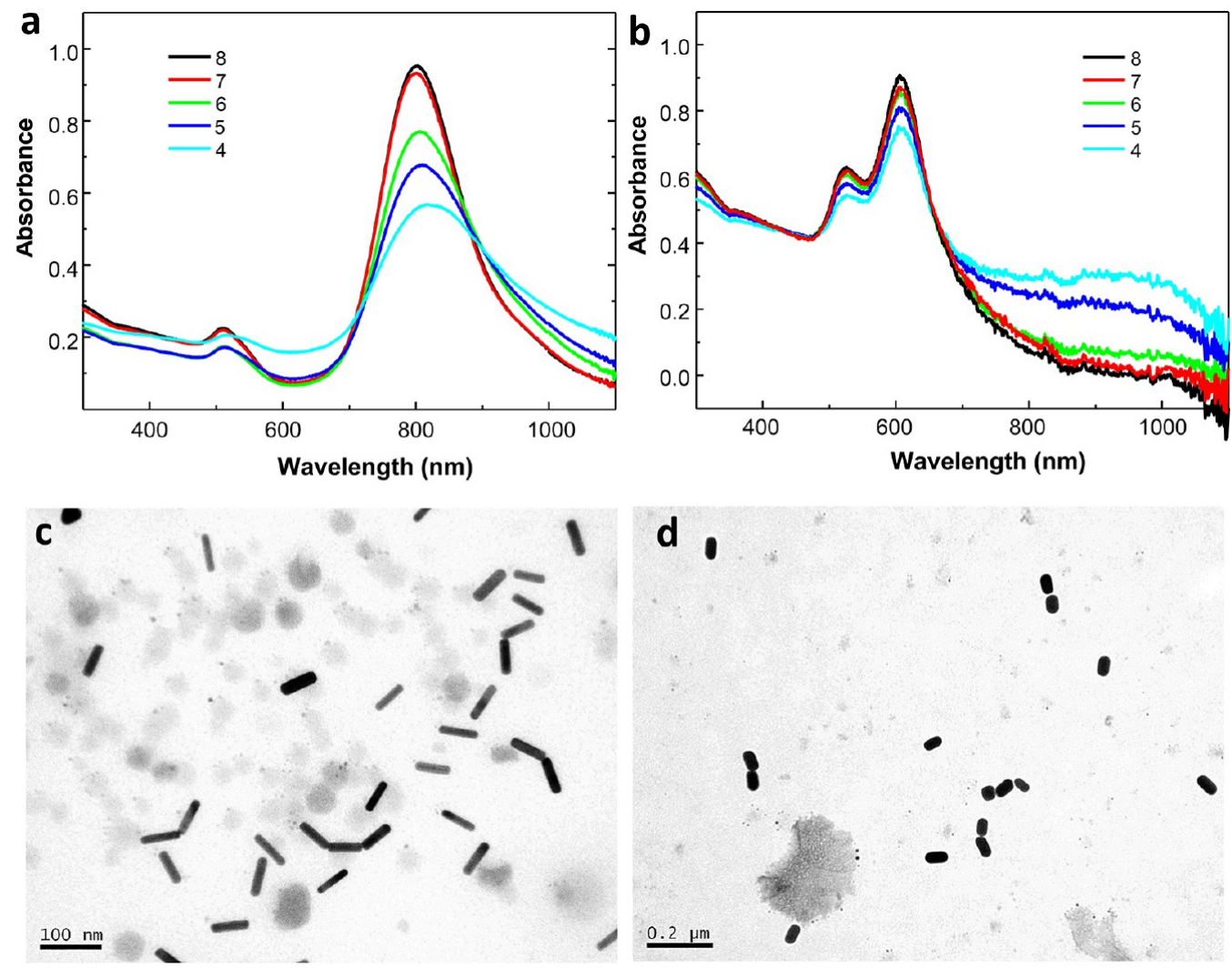

Figure 1. UV-vis-NIR spectra of Au NRs with L-LSPR bands at (a) $803 \mathrm{~nm}$ and (b) $604 \mathrm{~nm}$, functionalized with lipoic acid in the presence of PEG as a crowding agent in PBS solution at different $\mathrm{pH}$ values (from 8 to 4). Corresponding TEM micrographs of Au NRs with L-LSPR bands at (c) $803 \mathrm{~nm}$ and (d) $604 \mathrm{~nm}$ at $\mathrm{pH}$ 5, where tip-to-tip assembled Au NRs are observed. The observed dark background corresponds to the PEG used as the Au NR crowding agent.

subwavelength dimensions, ${ }^{18}$ the design of Au NPs with the ability to self-assemble inside the cell to obtain plasmonic assemblies is essential for PPTT. Interestingly, the characteristic acidic $\mathrm{pH}$ value within cell lysosomes $(\mathrm{pH} \leq 5),{ }^{19}$ where the $\mathrm{Au}$ NPs are mainly accumulated during the cell uptake process, ${ }^{20}$ has been used for PPTT purposes as an internal stimulus for the directed assembly of small $\mathrm{Au}$ nanospheres $(10 \mathrm{~nm}$ in diameter). ${ }^{21}$ Although such assemblies allow irradiation with low CW laser power densities $\left(5 \mathrm{~W} / \mathrm{cm}^{2}\right)$ to produce the optimal thermal cancer cell destruction, this value is still above the MPE threshold of skin; therefore, the development of $\mathrm{pH}$ controlled Au NP assemblies with higher plasmonic efficiencies is still a challenge.

Self-assembly studies have shown the ability of Au NRs functionalized with $\mathrm{pH}$-sensitive linking molecules to form tipto-tip ensembles at $\mathrm{pH}$ values that correspond with the $\mathrm{p} K_{\mathrm{a}}$ values of the linkers. ${ }^{22}$ Such assemblies are driven by the strong hydrogen bonding among the protonated states of the linking molecules at the tips of the Au NRs. Further, we have recently demonstrated that under fs laser irradiation the formation of tip-to-tip $\mathrm{Au} \mathrm{NR}$ oligomers produces longitudinal field enhancements up to 2 orders of magnitude higher than those of monomers, which are related to large temperature increases. $^{23,24}$

Inspired by these precedents, we have investigated the specific pH-driven tip-to-tip assembly of Au NRs (L-LSPR band at $\sim 800 \mathrm{~nm}$ ) within cancer cell lysosomes and the PPTT applicability of such ensembles for the in vitro photothermolysis of breast cancer cells (MDA-MB 231 cell line). The formation of intracellular plasmonic oligomers, combined with pulse laser irradiation at the NIR (800 nm Ti:sapphire 90 fs laser pulses, $80 \mathrm{MHz}$ ), has led to the optimization of the PPTT operating conditions, with minimum power density irradiations $\left(0.28 \mathrm{~W} / \mathrm{cm}^{2}\right.$, below the MPE threshold of skin), quantitative irradiation areas $\left(20 \mathrm{~mm}^{2}\right)$, and low incubation $\mathrm{Au}$ NR concentrations (10 pM). Moreover, we have realized a further enhancement of the applied PPTT using low-aspectratio Au NRs (L-LSPR band at $\sim 600 \mathrm{~nm}$ ) by maximizing the coupling between the L-LSPR band of the plasmonic oligomers and the wavelength of the fs pulses, allowing the reduction of the power density $\left(0.21 \mathrm{~W} / \mathrm{cm}^{2}\right)$ and Au NR dose $(1 \mathrm{pM})$.

\section{RESULTS AND DISCUSSION}

One of the main challenges in generating an intracellular tip-totip assembly of plasmonic Au NR oligomers and forming controlled hot spots as a tool for PPTT is the development of a successful Au NP functionalization strategy. This functionalization might be able to drive the tip-to-tip linkage of Au NRs in the very controlled environment of cells, while maintaining an acceptable cell uptake and good viability. After the optimized seed-mediated growth synthesis, ${ }^{25}$ the Au NRs were stabilized by a bilayer of the surfactant cetyltrimethylammonium bromide (CTAB), which, however, does not prevent particle aggregation at physiological ionic strength. ${ }^{26}$ This limitation has commonly been solved by CTAB ligand exchange with thiol-modified poly(ethylene glycol) (PEG-SH), which offers high Au NP biological stability ${ }^{27}$ and biocompatibility ${ }^{28}$ but reduces the $\mathrm{Au}$ NP cell uptake levels. ${ }^{29}$ For instance, charged functional groups have been introduced in the chemical structure of PEG-SH to significantly increase the cell internalization of $\mathrm{Au}$ NPs. ${ }^{30}$ 
a

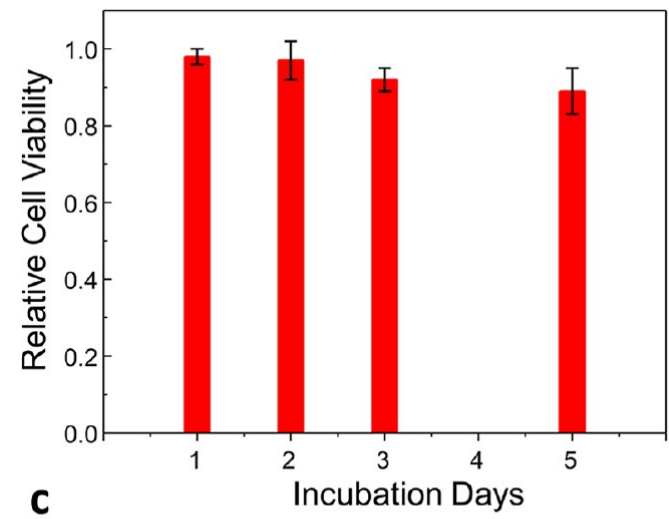

C

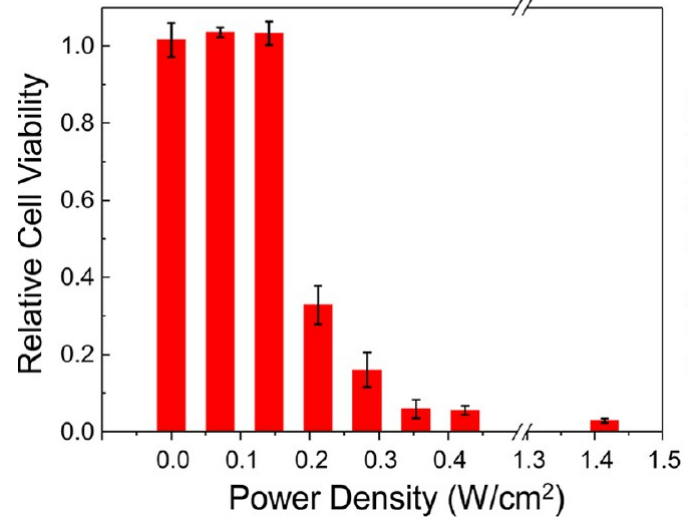

b
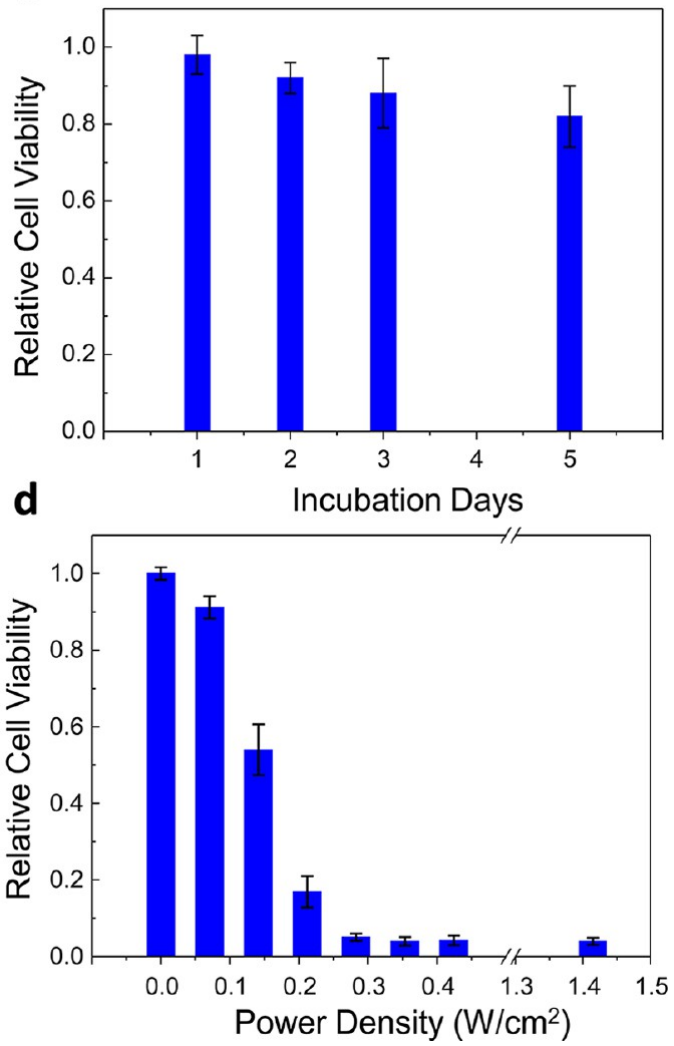

Figure 2. Representations of the cell viabilities at different incubation times in the presence of Au NRs with L-LSPR bands at (a) $803 \mathrm{~nm}$ and (b) $604 \mathrm{~nm}$, functionalized with lipoic acid. Cell viability as a function of the applied fs laser power density for Au NRs with L-LSPR bands at (c) $803 \mathrm{~nm}$ and (d) $604 \mathrm{~nm}$, functionalized with lipoic acid ( $800 \mathrm{~nm}$ Ti:sapphire 90 fs laser pulses, $80 \mathrm{MHz}, 20 \mathrm{~mm}^{2}$ exposure surface, 1 min irradiation time).

Following these functionalization considerations, we developed a two-step strategy based on (i) the initial PEGylation of $\mathrm{Au}$ NRs with PEG-SH (6 kDa), which confers the desired colloidal stability in cell culture media, and (ii) the subsequent specific Au NR tip functionalization with lipoic acid as a $\mathrm{pH}$ sensitive molecular linker. The choice of lipoic acid is based on its high biocompatibility as a cellular micronutrient (synthesized de novo in the mitochondria and/or by uptake), its antioxidant function (acting as scavenger of reactive oxygen species), ${ }^{31}$ and its bifunctional chemical structure (Figure S1), in which the presence of opposite disulfide and carboxyl groups $\left(\mathrm{p} K_{\mathrm{a}} \sim 5.0\right)$ may guarantee strong binding to the Au NP surface and protonation within the acidic cell lysosomes, respectively. This approach allows anisotropic functionalization, in which the Au NRs are specifically coated by PEG-SH and lipoic acid at their sides and tips, respectively.

So as to optimize the plasmonic system for PPTT, our strategy included the study of the influence of the $\mathrm{Au}$ NR aspect ratio (3.5 and 1.7, with L-LSPR bands at 803 and 604 $\mathrm{nm}$, respectively; Figures S2 and S3), the effect of functionalization (PEG-SH and its combination with lipoic acid), and the Au NR dose of incubation (decreasing from 0.1 $\mathrm{nM}$ to $0.01 \mathrm{pM})$. With regard to the pulse laser parameters $(800 \mathrm{~nm}$ Ti:sapphire $90 \mathrm{fs}, 80 \mathrm{MHz}$ ), we investigated the cell viability through the combination of previous experimental conditions at different laser power densities of irradiation (from 0 to $\left.1.41 \mathrm{~W} / \mathrm{cm}^{2}\right)$, maintaining a relatively high exposure surface $\left(20 \mathrm{~mm}^{2}\right)$ and low irradiation time $(1 \mathrm{~min})$.

To validate the proposed functionalization strategy, we evaluated the influence of $\mathrm{pH}$ on the tip-to-tip assembly of $\mathrm{Au}$
NRs by mimicking the conditions of the intracellular medium. For this purpose, we prepared sets of functionalized Au NRs (1 $\mathrm{nM}$ ) with both aspect ratios (3.5 and 1.7) in phosphatebuffered saline (PBS) solution at different $\mathrm{pH}$ values (decreasing from 8 to 4$)$. Additionally, PEG (1.5 kDa) was added as a particle crowding agent, where nonsignificant differences in the L-LSPR bands of Au NRs were observed, pointing to the suitability of the $\mathrm{Au} \mathrm{NR}$ macromolecular crowder (Figure S3). Under analogous $\mathrm{pH}$ titration as a control, no changes in the extinction bands of the Au NRs functionalized with PEG-SH in the absence of particle lipoic acid were detected (Figure S4), which confirms the high colloidal stability of the particles. However, the presence of lipoic acid at their tips dramatically changes the plasmonic features of the Au NRs below pH 6 (Figure 1a,b), showing a decrease in the L-LSPR band intensity along with the formation of new bands at the NIR ( $~ 900$ and $>1100$ for Au NRs, with LLSPR bands at 604 and $803 \mathrm{~nm}$, respectively), likely due to the formation of short tip-to-tip oligomers. ${ }^{23}$ We investigated the resulting assembled products using transmission electron microscopy (TEM), where a significant amount of tip-to-tip dimers, trimers, and tetramers was observed at $\mathrm{pH} 5\left(\mathrm{p} K_{\mathrm{a}}\right.$ of lipoic acid) (Figures 1c,d and S5). Therefore, under acidic conditions mimicking the typical $\mathrm{pH}$ of lysosomes, ${ }^{19}$ most of the carboxylic groups of lipoic acid are protonated and therefore directional intermolecular hydrogen bonding among the neutral linkers at the Au NR tips occurs. ${ }^{22}$

After the successful $\mathrm{pH}$-sensitive functionalization, the $\mathrm{Au}$ NRs were transferred to cell culture media supplemented with fetal bovine serum (FBS) and antibiotics. To determine the cell 

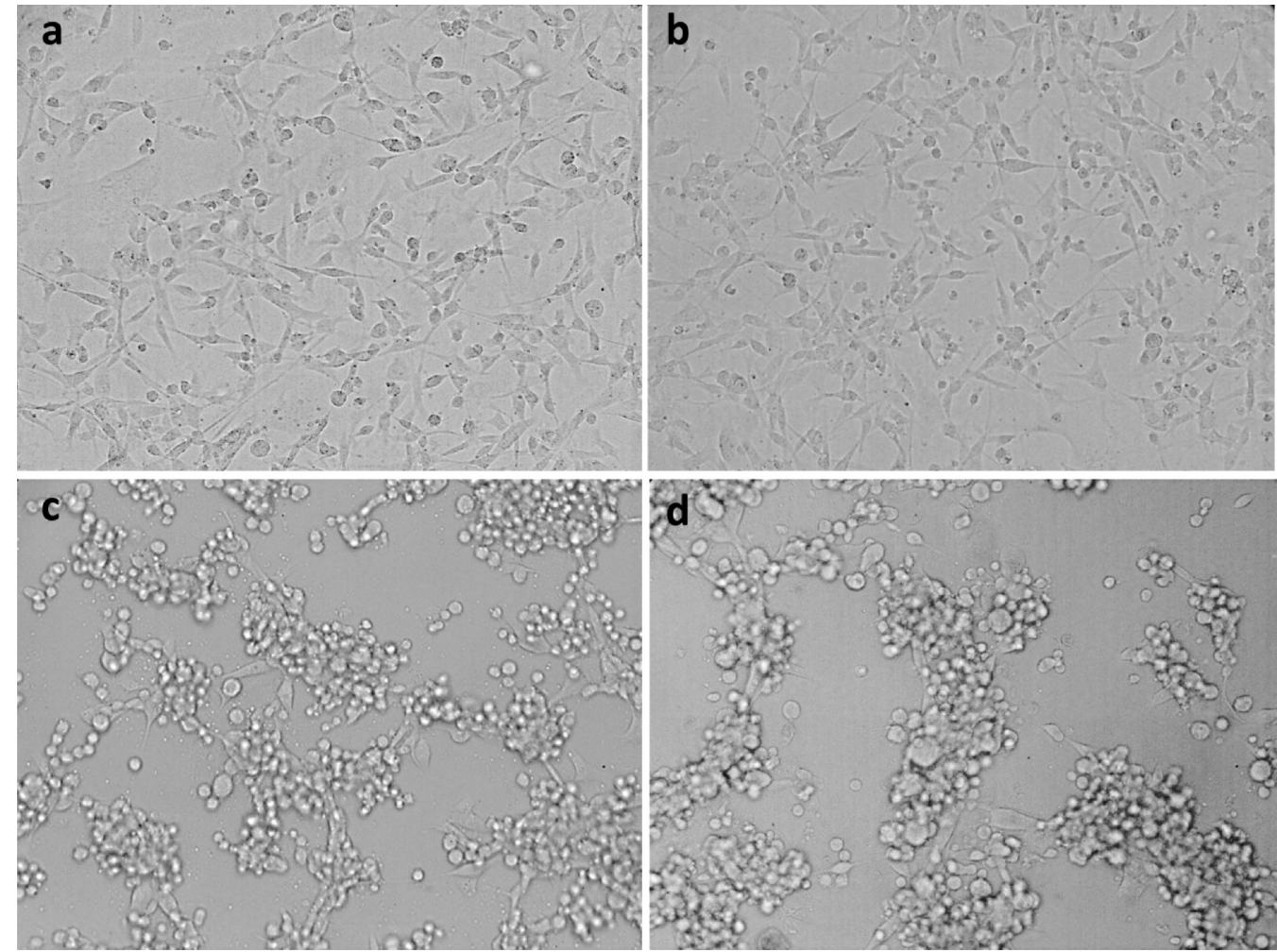

Figure 3. Bright-field images of MDA-MB 231 cells incubated with $0.1 \mathrm{nM}$ Au NRs (L-LSPR band at $803 \mathrm{~nm}$ ) after fs laser exposure with different laser power densities: (a) 0.07 , (b) 0.14 , (c) 0.21 , and (d) $0.28 \mathrm{~W} / \mathrm{cm}^{2}$.
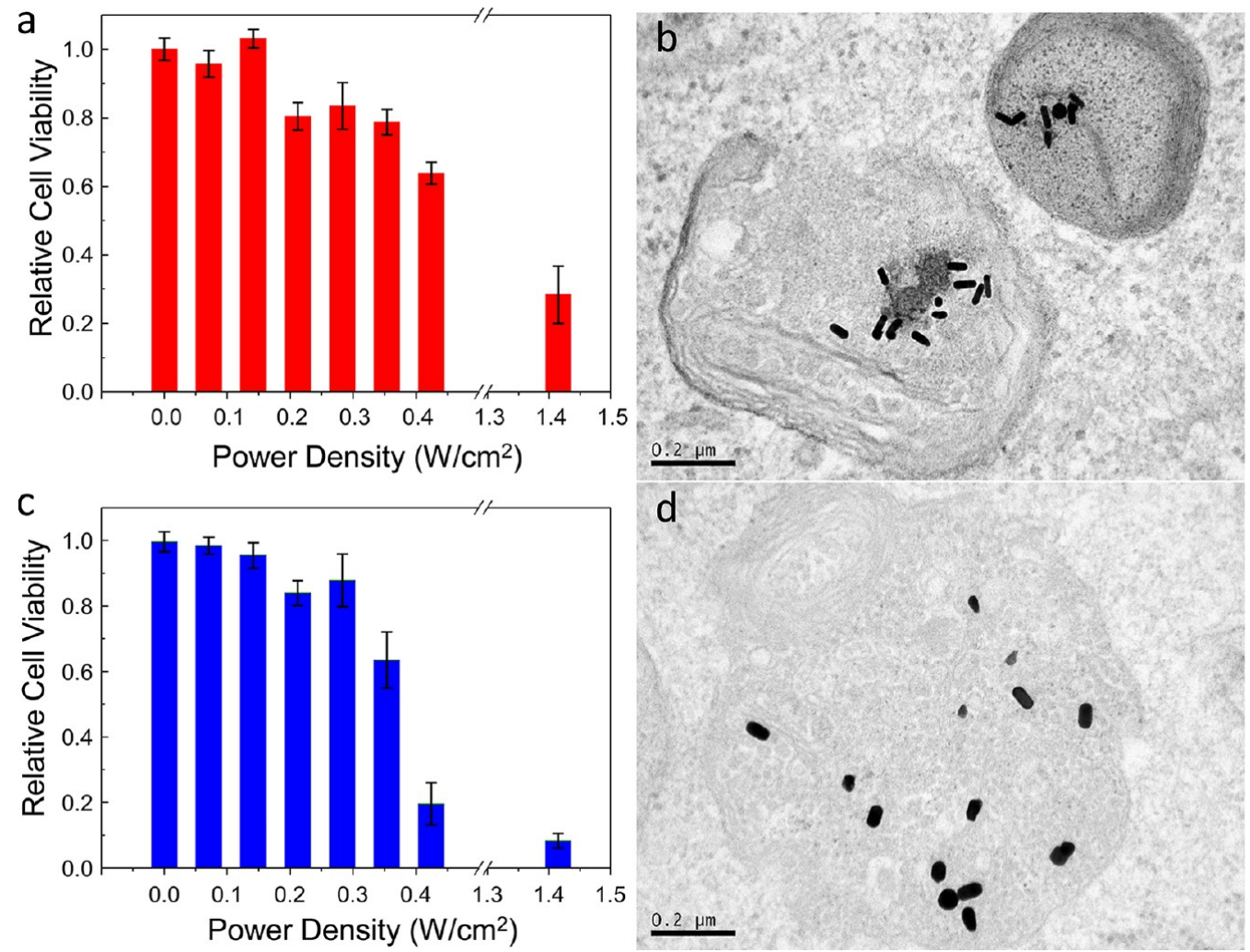

Figure 4. (a) Cell viability as a function of the applied fs laser power density for Au NRs with the L-LSPR band at $803 \mathrm{~nm}$ without lipoic acid functionalization. (b) Typical TEM magnifications of a lysosome after incubation with the Au NRs used in (a). (a) Cell viability as a function of the applied fs laser power density for Au NRs with the L-LSPR band at $604 \mathrm{~nm}$ without lipoic acid functionalization. (b) Typical TEM magnifications of a lysosome after incubation with the Au NRs used in (c). The estimated uptake values are $4900 \pm 1000$ (b) and $6100 \pm 1800$ (d) Au NRs per cell. 


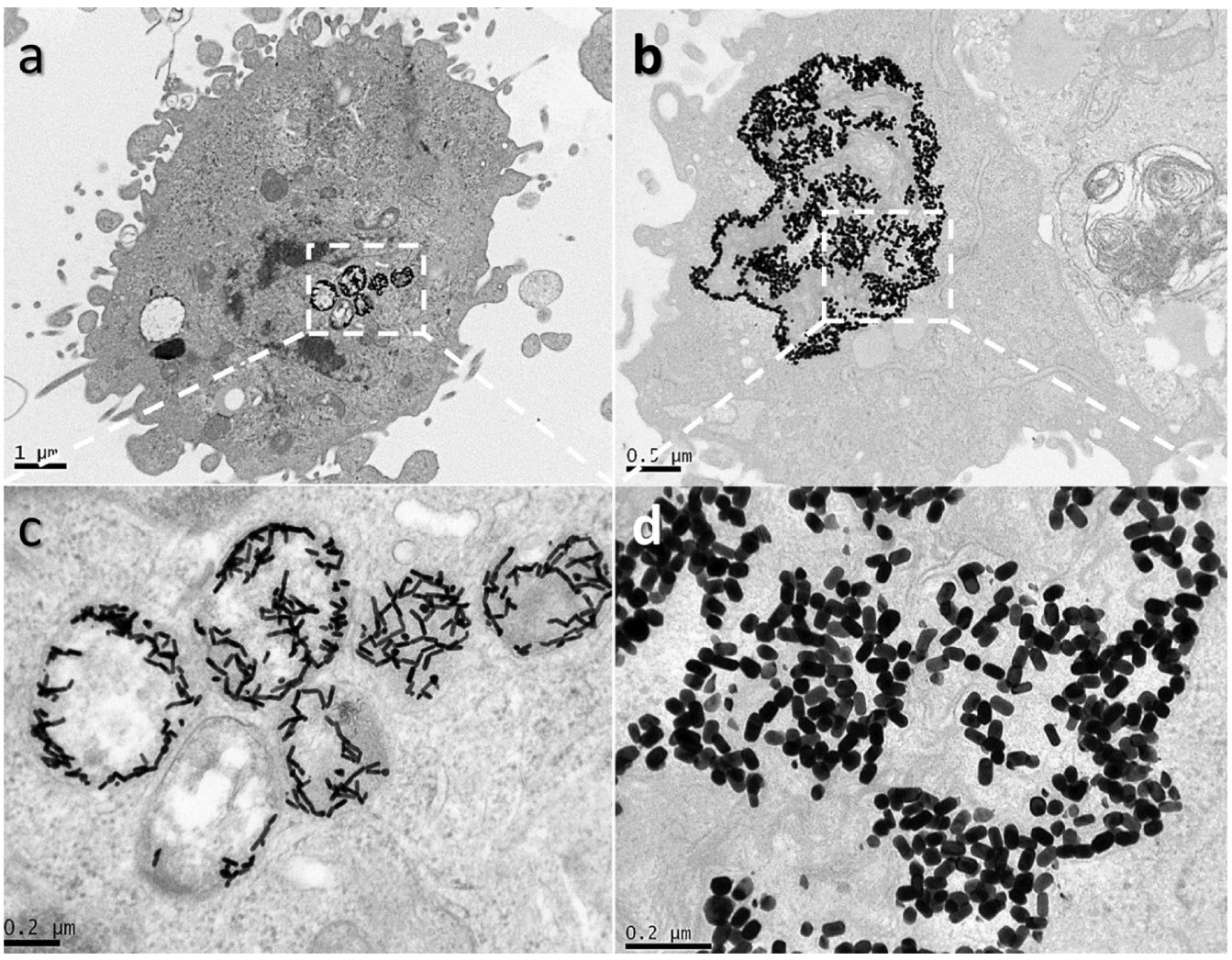

Figure 5. Representative TEM micrographs of cancer MDA-MB-231 cells after $24 \mathrm{~h}$ of incubation with $0.1 \mathrm{nM}$ Au NRs with LSPR bands at (a) 803 $\mathrm{nm}$ and (b) $604 \mathrm{~nm}$, functionalized with lipoic acid. (c) and (d) correspond to magnifications of the lysosome areas in (a) and (b), respectively. The estimated uptake values are $21400 \pm 6500$ (a) and $19300 \pm 5200$ (b) Au NRs per cell.

viability, we incubated breast cancer cells (MDA-MB-231) with $0.1 \mathrm{nM} \mathrm{Au}$ NRs. Regardless of the aspect ratio, the cell viability values ( $20-100 \%)$ remained close to those of the control experiments in the absence of irradiation for all different functionalizations and incubation times ( $1-5$ days) (Figures 2a,b and S6). Initially, photothermolysis of the cancer cells was tested by fs laser irradiation at different power densities of the samples incubated with Au NRs $\left(\lambda_{\text {L-LSPR }}\right.$ at $\left.803 \mathrm{~nm}\right)$ for $24 \mathrm{~h}$ (Figures $2 \mathrm{c}$ and 3 ). The use of PEG-SH as a capping agent of $\mathrm{Au}$ NRs guarantees the absence of singlet oxygen generation upon pulse laser irradiation with low power densities (below the MPE threshold of skin), which excludes photodynamic processes from PPTT. ${ }^{32}$ At a power density of $0.28 \mathrm{~W} / \mathrm{cm}^{2}$, a large killing rate (up to 85\%) was observed for cells incubated with $\mathrm{Au}$ NRs functionalized with lipoic acid. Under the same conditions, the killing rate was enhanced up to $95 \%$ on using the $\mathrm{Au}$ NRs with $\lambda_{\mathrm{L}-\mathrm{LSPR}}$ at $604 \mathrm{~nm}$ (Figure 2d). Interestingly, the short-aspect-ratio $\mathrm{Au}$ NRs showed an excellent killing efficiency $(\sim 85 \%)$ at an even lower power density of $0.21 \mathrm{~W} /$ $\mathrm{cm}^{2}$, which indicates that the L-LSPR band of the Au NRs may be placed at lower wavelengths with respect to the fs pulses to achieve optimal PPTT. In the absence of lipoic acid functionalization, the laser power density had to be increased up to $1.41 \mathrm{~W} / \mathrm{cm}^{2}$ (above the MPE threshold of skin) to obtain similar killing rates (70-90\%) with Au NRs of both aspect ratios (Figure 4a,c). At this point, it is important to note that the use of lipoic acid as a Au NP ligand leads to high killing rates using very low laser power densities, which are indeed $\sim 6$ times lower than those needed with $\mathrm{Au}$ nanocages ${ }^{10}$ and of the same order as those required with Au nanostars, ${ }^{15}$ which are known to be more efficient plasmonic systems than isolated $\mathrm{Au}$
NRs. ${ }^{33,34}$ Irradiation at such low fluences, in the range of 2-20 $\mathrm{nJ} / \mathrm{cm}^{2}$ per pulse, would be translated into local temperature increments of a few degrees for single Au NRs in water. ${ }^{35}$ Therefore, we suspected the formation of intracellular hot spots with likely larger temperatures, but below the thermal decomposition temperature of molecular linkers (typically around $450 \mathrm{~K}){ }^{23}$ by $\mathrm{Au} \mathrm{NR}$ tip-to-tip assembly, as seen in the $\mathrm{pH}$ titration experiments.

TEM microscopy was used to gain insight into the $\mathrm{Au}$ NR cell uptake and morphology of the intracellular Au nanostructures (Figures 5a,b, S7, and S8). After $24 \mathrm{~h}$ of cell incubation with Au NRs, a large amount of large tip-to-tip oligomers was observed within the cell lysosomes, as proof of the proposed $\mathrm{Au}$ NR functionalization strategy for enhanced PPTT. The formation of oligomers can be rationalized by the acidic microenvironment inside the lysosomes $(\mathrm{pH} \leq 5) .{ }^{19}$ The noticeable improvement in the yield of the assembled species with respect to that in the $\mathrm{pH}$ titration experiments (Figure $1 \mathrm{c}, \mathrm{d})$ can be explained considering the Au NP confinement in the lysosomes and the observed templating effect at the organelle membrane (Figures 5c,d, S7, and S8). Lower uptake levels and nonspecific assembly were observed by TEM in the case of $\mathrm{Au}$ NRs without lipoic acid functionalization (Figure $4 \mathrm{~b}, \mathrm{~d})$.

At this point, we wondered about the dependence of the killing rate levels on the uptake degree and/or hot-spot formation. To determine the driving factor, we prepared sets of experiments by incubating the cells with Au NRs at both aspect ratios, functionalized with lipoic acid at different Au NR doses (from $0.1 \mathrm{nM}$ to $0.01 \mathrm{pM}$ ). Figure 6a shows that $\mathrm{Au} \mathrm{NRs}$ $\left(\lambda_{\mathrm{L}-\mathrm{LSPR}}\right.$ at $\left.803 \mathrm{~nm}\right)$ lead to efficient photothermolysis ( 90\%) 
a
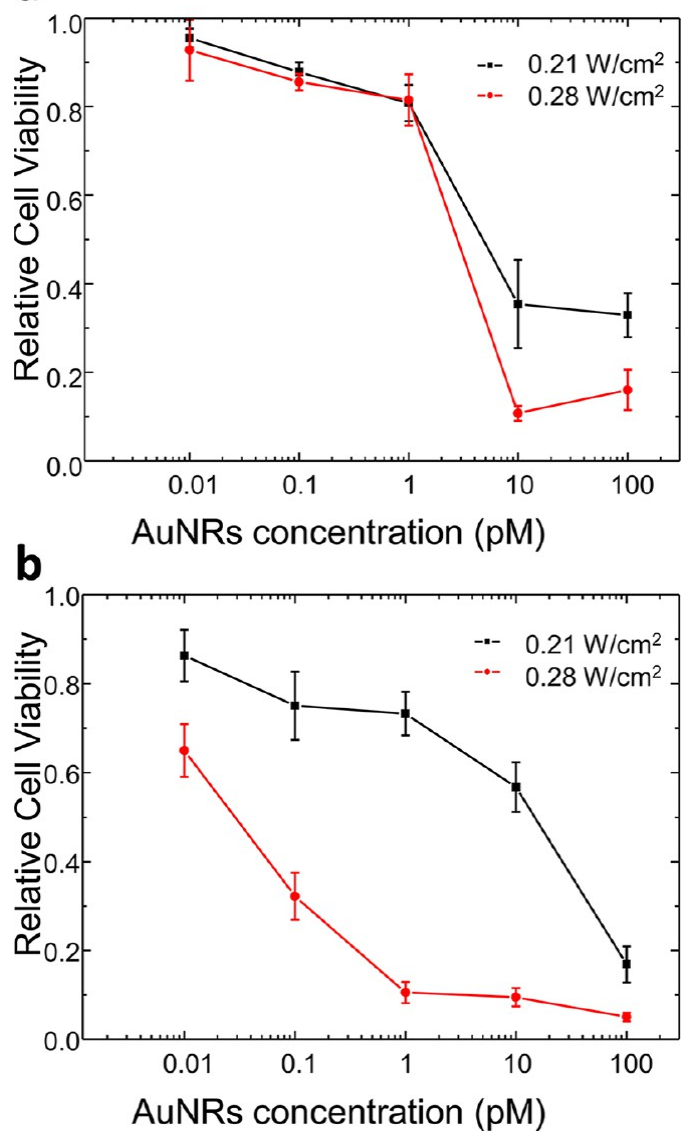

Figure 6. Cell viability as a function of the Au NR incubation concentration after irradiation with different fs laser power densities $\left(0.21\right.$ and $\left.0.28 \mathrm{~W} / \mathrm{cm}^{2}\right)$ for Au NRs with LSPR bands at (a) $803 \mathrm{~nm}$ and (b) $604 \mathrm{~nm}$, functionalized with lipoic acid (800 nm Ti:sapphire $90 \mathrm{fs}$ laser pulses, $80 \mathrm{MHz}, 20 \mathrm{~mm}^{2}$ exposure surface, 1 min irradiation time).

at concentrations of $10 \mathrm{pM}$ and laser power densities of 0.28 $\mathrm{W} / \mathrm{cm}^{2}$, whereas analogous cell killing rates were obtained with $\mathrm{Au}$ NRs with the L-LSPR band at $604 \mathrm{~nm}$ at the same laser power densities but concentrations of $1 \mathrm{pM}$ (Figure 6b). Therefore, and considering that $\mathrm{Au}$ NRs without lipoic acid provide comparable killing rates at concentrations of $0.1 \mathrm{nM}$ and laser power densities of $1.41 \mathrm{~W} / \mathrm{cm}^{2}$ (Figure 4), the uptake effect on PPTT can be considered less significant than the plasmonic efficiency by hot-spot formation. This conclusion is in good agreement with the uptake levels estimated for the different Au NRs and functionalizations through TEM analysis (Figures S7 and S8). ${ }^{30}$ Limited by the wavelength of the available fs lasers, these results highlight the importance of using $\mathrm{Au}$ NRs with low aspect ratios for the preparation of intracellular $\mathrm{pH}$-induced tip-to-tip assembled oligomers for PPTT purposes.

\section{CONCLUSIONS}

Our investigations have shown that Au NRs, and in particular the ones stabilized with lipoic acid, form tip-to-tip assemblies within model cancer cell lysosomes, which considerably reduce the NIR fs laser power density irradiation required for efficient PPTT $\left(0.28 \mathrm{~W} / \mathrm{cm}^{2}\right.$, below the MPE threshold of skin) with respect to that needed with random Au NR aggregates (1.41 $\mathrm{W} / \mathrm{cm}^{2}$ ). The $\mathrm{pH}$-induced directional intermolecular hydrogen bonding between lipoic acid molecules at the tips of the $\mathrm{Au}$ NRs and the lysosome membrane confinement explain the massive formation of intracellular oligomers. Under low fs laser irradiation conditions, the temperature increase at the interparticle gaps of the oligomers is large enough to induce effective cell death. The formation of Au NR oligomers with low aspect ratios allows an important reduction in the applied laser power density (down to $0.21 \mathrm{~W} / \mathrm{cm}^{2}$ ). Therefore, the selfassembly of plasmonic tip-to-tip oligomers with L-LSPR bands close in resonance with the NIR wavelength of the fs laser was found to be the decisive phenomenon for the enhanced PPTT. Such low power densities are comparable to those obtained with highly plasmonically active Au nanostars $\left(0.2 \mathrm{~W} / \mathrm{cm}^{2}\right){ }^{15}$ however, they were achieved at Au NP doses of incubation 2 orders of magnitude lower $(1 \mathrm{pM})$. Moreover, good death rates of $70 \%$ were obtained at a Au NR incubation concentration of $0.1 \mathrm{pM}$. Thus, the intracellular self-assembly strategy demonstrated here opens new prospects in Au NP functionalization to drive the generation of controlled hot spots in cell organelles, drastically reducing the aggressiveness of both pulse laser irradiation and $\mathrm{Au} \mathrm{NP}$ dose in current cancer photothermal therapies.

\section{EXPERIMENTAL SECTION}

Materials. Reagents, metal-salt precursors, buffers, culture media, and other analytical grade chemicals were purchased from Sigma-Aldrich or Merck. Deionized water from a Millipore system (>18 M ; Milli $\mathrm{Q})$ was used in all experiments.

Optical Characterization. UV-vis-NIR absorption spectra were recorded using a JASCO-V770 spectrophotometer, with a spectral bandwidth of $1.0 \mathrm{~nm}$ and a scan rate of $200 \mathrm{~nm} /$ min. All experiments were carried out using quartz cuvettes with a $1 \mathrm{~cm}$ optical path.

Synthesis of Au NRs $\left(\lambda_{\text {L-LSPR }}\right.$ at $\left.803 \mathrm{~nm}\right)$. The seeds were prepared by the standard $\mathrm{CTAB} / \mathrm{NaBH}_{4}$ procedure: $25 \mu \mathrm{L}$ of a $0.05 \mathrm{M} \mathrm{HAuCl}_{4}$ solution was added to $4.7 \mathrm{~mL}$ of a $0.1 \mathrm{M}$ CTAB solution; $300 \mu \mathrm{L}$ of a freshly prepared $0.01 \mathrm{M} \mathrm{NaBH}_{4}$ solution was then injected under vigorous stirring. Any excess of borohydride was consumed by keeping the seed solution for $30 \mathrm{~min}$ at room temperature before use. $\mathrm{Au}$ NRs were prepared, with some modifications, as previously described. ${ }^{25}$ For the synthesis of $50 \mathrm{~mL}$ of a Au NR solution, $45 \mathrm{mg}$ of 5bromosalicylic acid was added to $50 \mathrm{~mL}$ of $0.05 \mathrm{M} \mathrm{CTAB}$. The solution was mildly stirred for $15 \mathrm{~min}$ until complete dissolution, and $480 \mu \mathrm{L}$ of $0.01 \mathrm{M} \mathrm{AgNO}_{3}$ and $500 \mu \mathrm{L}$ of $0.05 \mathrm{M} \mathrm{HAuCl}_{4}$ were added to the mixture. After $30 \mathrm{~min}$ at 25 ${ }^{\circ} \mathrm{C}, 130 \mu \mathrm{L}$ of a $0.1 \mathrm{M}$ ascorbic acid solution was added under vigorous stirring, followed by $80 \mu \mathrm{L}$ of the seed solution. The mixture was left undisturbed at room temperature for at least 4 h. The resulting Au NRs displayed an L-LSPR with an absorption maximum at $803 \mathrm{~nm}$. The resulting CTAB-stabilized $\mathrm{Au}$ NRs presented a length and diameter of $56 \pm 4$ and $16 \pm 2$ $\mathrm{nm}$, respectively, with an aspect ratio of 3.6 , as determined from TEM images.

Synthesis of Au NRs $\left(\lambda_{\text {L-LSPR }}\right.$ at $\left.604 \mathrm{~nm}\right)$. In a typical synthesis of $50 \mathrm{~mL}$ of a Au NR solution, $45 \mathrm{mg}$ of 5bromosalicylic acid was added to $50 \mathrm{~mL}$ of $0.05 \mathrm{M} \mathrm{CTAB}$. The solution was stirred for 15 min until complete dissolution, and $480 \mu \mathrm{L}$ of $0.01 \mathrm{M} \mathrm{AgNO}_{3}$ and $500 \mu \mathrm{L}$ of $0.05 \mathrm{M} \mathrm{HAuCl}_{4}$ were added to the mixture. After $2 \mathrm{~h}$ at $25^{\circ} \mathrm{C}, 130 \mu \mathrm{L}$ of a $0.1 \mathrm{M}$ ascorbic acid solution was added under vigorous stirring, followed by $80 \mu \mathrm{L}$ of the seed solution (described previously 
for $\mathrm{Au}$ NRs with $\lambda_{\mathrm{L}-\mathrm{LSPR}}$ at $803 \mathrm{~nm}$ ). The mixture was left undisturbed at room temperature for at least $4 \mathrm{~h}$. The resulting $\mathrm{Au}$ NRs presented an L-LSPR band with a maximum at 660 $\mathrm{nm}$. Typically, $50 \mathrm{~mL}$ of the mixture was centrifuged $(6000$ $\mathrm{rpm}, 30 \mathrm{~min}$ ), and the pellet was redispersed in the same volume of a solution of $0.05 \mathrm{M} \mathrm{CTAB}$, containing $45 \mathrm{mg}$ of 5bromosalicylic acid, $700 \mu \mathrm{L}$ of $0.01 \mathrm{M} \mathrm{AgNO}_{3}, 500 \mu \mathrm{L}$ of 0.05 $\mathrm{M} \mathrm{HAuCl}_{4}$, and $250 \mu \mathrm{L}$ of ascorbic acid. The solution was slowly heated to $90{ }^{\circ} \mathrm{C}$ in a water bath, and the temperature was maintained until the L-LSPR band of the Au NRs blueshifted to $604 \mathrm{~nm}$. At this point, the mixture was rapidly cooled, and the Au NRs were washed by centrifugation $(6000 \mathrm{rpm}, 30$ $\mathrm{min})$. Finally, the $\mathrm{Au}$ NRs were redispersed in $10 \mathrm{~mL}$ of a 2 $\mathrm{mM} C \mathrm{CTAB}$ solution. The resulting CTAB-stabilized Au NRs presented a length and diameter of $58 \pm 4 \mathrm{~nm}$ and $34 \pm 4 \mathrm{~nm}$, respectively, with an aspect ratio of 1.7 , as determined from TEM images.

PEG Stabilization. The CTAB-stabilized Au NR dispersion $(10 \mathrm{~mL})$ was washed by centrifugation at $6000 \mathrm{rpm}$ for $30 \mathrm{~min}$. After carefully removing the supernatant, the Au NRs were resuspended in a solution containing $2 \mathrm{mM}$ PEG $(6 \mathrm{kDa})$ in Milli $\mathrm{Q}$ water for $2 \mathrm{~h}$, with gentle stirring. The resulting mixture was incubated overnight at room temperature.

Lipoic Acid Functionalization. A solution of lipoic acid (1 $\mathrm{mM}$ as the final concentration) in Hepes buffer $(\mathrm{pH} 8)$ was added to the concentrated solution of PEG-stabilized nanorods. The mixture was stirred for $1 \mathrm{~h}$ and further incubated for $2 \mathrm{~h}$ at room temperature. Then, the Au NRs were washed to remove the unreacted molecules, with two centrifugation cycles (at $3000 \mathrm{rpm}$ for $60 \mathrm{~min}$ ). The functionalized $\mathrm{Au}$ NRs were colloidally stable in PBS buffer as well as in culture media.

pH Titration Experiments. Au NRs stabilized with lipoic acid $(1 \mathrm{nM})$ in PBS buffer and supplemented with $50 \mathrm{~g} / \mathrm{L}$ PEG $(1.5 \mathrm{kDa})$ were mixed with small volumes of a diluted solution of $\mathrm{HCl}(0.01 \mathrm{M})$ to reach different $\mathrm{pH}$ values (from 8 to 4 ).

Cell Culture and Viability. Human MDA-MB-231 breast epithelial cells were purchased from the European Collection of Cell Cultures (ECACC, Salisbury, UK). The cells were grown in Dulbecco's modified Eagle's medium (DMEM, Gibco; Life Technologies Corporation, Rockville, MD) supplemented with $10 \% \mathrm{FBS}, 500 \mathrm{UI} / \mathrm{mL}$ penicillin, and $0.1 \mathrm{mg} / \mathrm{mL}$ streptomycin and maintained at $37{ }^{\circ} \mathrm{C}$ in $5 \% \mathrm{CO}_{2}$ in a humidified incubator until confluence. The cell viability after $1-3$ and 5 days of incubation with $0.1 \mathrm{nM} \mathrm{Au}$ NRs was evaluated with the Alamar Blue assay (Life Technologies). The cells were incubated in a 96-well plate with $10 \%$ Alamar Blue in DMEM without red phenol for $3 \mathrm{~h}$ following the guidelines of the commercial kit. The absorbance at $570 \mathrm{~nm}$ was followed, using $600 \mathrm{~nm}$ as the reference wavelength. The viability was determined by comparison with control cells (100\%). All reported experiments were performed at least in triplicate.

PPTT. Photothermal irradiation was carried out with a pulsed laser system, Ti:sapphire ultrafast oscillator (Tsunami, Spectra-Physics), with a pulse duration of $90 \mathrm{fs,} \mathrm{a} \mathrm{repetition} \mathrm{rate}$ of $80 \mathrm{MHz}$, and centered at $800 \mathrm{~nm}$. The laser power density was controlled by a variable neutral density filter. Au NRs were incubated at concentrations from $0.1 \mathrm{nM}$ to $0.01 \mathrm{pM}$ for $24 \mathrm{~h}$; therafter, the cells were washed twice with PBS buffer and fresh supplemented DMEM was added. The incubated cells contained in a 96-well plate $\left(7 \times 10^{3}\right.$ cells/well $)$ were illuminated for $1 \mathrm{~min}$, with a laser spot diameter of $5 \mathrm{~mm}$. The laser power was evaluated from 0 to $1.41 \mathrm{~W} / \mathrm{cm}^{2}$. After irradiation, the cells were incubated in a 96-well plate with $10 \%$
Alamar Blue in DMEM without red phenol for $3 \mathrm{~h}$, following the guidelines of the commercial kit. The absorbance at $570 \mathrm{~nm}$ was followed, using $600 \mathrm{~nm}$ as the reference wavelength. The viability was determined by comparison with control cells (100\%). All reported experiments were performed at least in triplicate.

TEM. TEM images were obtained with a JEOL JEM-1010 transmission electron microscope, operating with an acceleration of $80 \mathrm{kV}$ (CNME, Spain). The cells were incubated with Au NRs, washed, and fixed with $2 \%$ glutaraldehyde in PBS buffer; then, they were stained with $1 \%$ osmium tetroxide and $1.5 \%$ potassium cyanoferrate and gradually dehydrated in acetone. The samples were embedded in Epon, sectioned for analysis, and cut by ultramicrotomy to $60 \mathrm{~nm}$ sections for observation. The Au NR uptake levels were estimated from the TEM images, following the procedure described in the literature. $^{30}$

\section{ASSOCIATED CONTENT}

\section{Supporting Information}

The Supporting Information is available free of charge on the ACS Publications website at DOI: 10.1021/acsomega.6b00184.

Chemical structure of lipoic acid; TEM micrographs and UV-vis-NIR spectra of the synthesized Au NRs; pH titrations by UV-vis-NIR spectroscopy of Au NRs stabilized with PEG; TEM details of extra- and intracellular tip-to-tip Au NR oligomers; viability results of $\mathrm{Au}$ NRs stabilized with PEG; and TEM details of the interaction between $\mathrm{Au} \mathrm{NRs}$ and the lysosome membrane (PDF)

\section{AUTHOR INFORMATION}

\section{Corresponding Authors}

*E-mail: rahijado@ucm.es (R.A.-G.).

*E-mail: aguerrero@quim.ucm.es (A.G.-M.).

\section{Notes}

The authors declare no competing financial interest.

\section{ACKNOWLEDGMENTS}

This work has been funded by the Spanish MINECO (MAT2014-59678-R and CTQ2012-37404-C02-01) and the Madrid Regional Government (S2013/MIT-2807). A.C.-M. and M.C. and I.L.-M. acknowledge the financial support of the ERC Starting Grants "NANOFORCELLS" (ERC-StG-2011278860) and "MITOCHON" (ERC-StG-2013-338133). A.G.M. and I.L.-M. acknowledge receipt of Ramón y Cajal Fellowships from the Spanish MINECO. G.G.-R. acknowledges receipt of the FPI Fellowship from the Spanish MINECO. The facilities provided by the Ultrafast Lasers Center and National Center of Microscopy at Complutense University of Madrid are gratefully acknowledged.

\section{REFERENCES}

(1) Huang, X.; Jain, P. K.; El-Sayed, I. H.; El-Sayed, M. A. Plasmonic photothermal therapy (PPTT) using gold nanoparticles. Lasers Med. Sci. 2008, 23, 217-228.

(2) Guerrero-Martínez, A.; Grzelczak, M.; Liz-Marzán, L. M. Molecular thinking for nanoplasmonic design. ACS Nano 2012, 6, 3655-3662.

(3) Pérez-Juste, J.; Pastoriza-Santos, I.; Liz-Marzán, L. M.; Mulvaney, P. Gold Nanorods: Synthesis, Characterization and Applications. Coord. Chem. Rev. 2005, 249, 1870-1901. 
(4) Becker, J.; Trügler, A.; Jakab, A.; Hohenester, U.; Sönnichsen, C. The Optimal Aspect Ratio of Gold Nanorods for Plasmonic Biosensing. Plasmonics 2010, 5, 161-167.

(5) Weissleder, R. A clearer vision for in vivo imaging. Nat. Biotechnol. 2001, 19, 316-317.

(6) Lukianova-Hleb, E. Y.; Kim, Y.-S.; Beatsarkouski, I.; Gillenwater, A. M.; O’Neill, B. E.; Laptoko, D. O. Intraoperative diagnostics and elimination of residual microtumours with plasmonic nanobubbles. Nat. Nanotechnol. 2016, 11, 525-532.

(7) Abadeer, N. S.; Murphy, C. J. Recent Progress in Cancer Thermal Therapy Using Gold Nanoparticles. J. Phys. Chem. C 2016, 120, 46914716.

(8) González-Rubio, G.; Guerrero-Martínez, A.; Liz-Marzán, L. M. Reshaping, Fragmentation and Assembly of Gold Nanoparticles Assisted by Pulse Lasers. Acc. Chem. Res. 2016, 49, 678-686.

(9) Pérez-Hernández, M.; Del Pino, P.; Mitchell, S. G.; Moros, M.; Stepien, G.; Pelaz, B.; Parak, W. J.; Gálvez, E. M.; Pardo, J.; Martínez de la Fuente, J. Dissecting the Molecular Mechanism of Apoptosis during Photothermal Therapy Using Gold Nanoprisms. ACS Nano 2015, 9, 52-61.

(10) Chen, J.; Wang, D.; Xi, J.; Au, L.; Siekkinen, A.; Warsen, A.; Li, Z. Y.; Zhang, H.; Xia, Y.; Li, X. Immuno Gold Nanocages with Tailored Optical Properties for Targeted Photothermal Destruction of Cancer Cells. Nano Lett. 2007, 7, 1318-1322.

(11) Liu, Y.; Yang, M.; Zhang, J.; Zhi, X.; Li, C.; Zhang, C.; Pan, F.; Wang, K.; Yang, Y.; Martínez de la Fuente, J.; Cui, D. Human Induced Pluripotent Stem Cells for Tumor Targeted Delivery of Gold Nanorods and Enhanced Photothermal Therapy. ACS Nano 2016, $10,2375-2385$.

(12) El-Sayed, I. H.; Huang, X.; El-Sayed, M. A. Selective laser photothermal therapy of epithelial carcinoma using anti-EGFR antibody conjugated gold nanoparticles. Cancer Lett. 2006, 239, 129-135.

(13) Huang, X.; Kang, B.; Qian, W.; Mackey, M. A.; Chen, P. C.; Oyelere, A. K.; El-Sayed, I. H.; El-Sayed, M. A. Comparative study of photothermolysis of cancer cells with nuclear-targeted or cytoplasmtargeted gold nanospheres: continuous wave or pulsed lasers. J. Biomed. Opt. 2010, 15, No. 058002, DOI: 10.1117/1.3486538.

(14) American National Standard for Safe Use of Lasers; Laser Institute of America: Orlando, FL, 2000.

(15) Yuan, H.; Fales, A. M.; Vo-Dinh, T. TAT Peptide-Functionalized Gold Nanostars: Enhanced Intracellular Delivery and Efficient NIR Photothermal Therapy Using Ultralow Irradiance. J. Am. Chem. Soc. 2012, 134, 11358-11361.

(16) Klinkova, A.; Choueiri, R. M.; Kumacheva, E. Self-assembled plasmonic nanostructures. Chem. Soc. Rev. 2014, 43, 3976-3991.

(17) Álvarez-Puebla, R.; Liz-Marzán, L. M.; García de Abajo, F. J. Light Concentration at the Nanometer Scale. J. Phys. Chem. Lett. 2010, $1,2428-2434$.

(18) Herrmann, L. O.; Valev, V. K.; Tserkezis, C.; Barnard, J. S.; Kasera, S.; Scherman, O. A.; Aizpurua, J.; Baumberg, J. J. Threading plasmonic nanoparticle strings with light. Nat. Commun. 2014, 5, No. 4568.

(19) Mindell, J. A. Lysosomal acidification mechanisms. Annu. Rev. Physiol. 2012, 74, 69-86.

(20) Ma, X.; Wu, Y.; Jin, S.; Tian, Y.; Zhang, X.; Zhao, Y.; Yu, L.; Liang, X. J. Gold Nanoparticles Induce Autophagosome Accumulation through Size-Dependent Nanoparticle Uptake and Lysosome Impairment. ACS Nano 2011, 5, 8629-8639.

(21) Nam, J.; Won, N.; Jin, H.; Chung, H.; Kim, S. pH-Induced Aggregation of Gold Nanoparticles for Photothermal Cancer Therapy. J. Am. Chem. Soc. 2009, 131, 13639-13645.

(22) Ni, W.; Mosquera, R. A.; Pérez-Juste, J.; Liz-Marzán, L. M. Evidence for Hydrogen Bonding-Directed Assembly of Gold Nanorods in Aqueous Solution. J. Phys. Chem. Lett. 2010, 1, 1181-1185.

(23) González-Rubio, G.; González-Izquierdo, J.; Bañares, L.; Tardajos, G.; Rivera, A.; Altantzis, T.; Bals, S.; Peña-Rodríguez, O.; Guerrero-Martínez, A.; Liz-Marzán, L. M. Femtosecond LaserControlled Tip-to-tip Assembly and Welding of Gold Nanorods. Nano Lett. 2015, 15, 8282-8288.
(24) Link, S.; Wang, Z. L.; El-Sayed, M. A. How does a gold nanorod melt? J. Phys. Chem. B 2000, 104, 7867-7870.

(25) Ye, X.; Jin, L.; Caglayan, H.; Chen, J.; Xing, G.; Zheng, C.; Doan-Nguyen, V.; Kang, Y.; Engheta, N.; Kagan, C. R.; Murray, C. B. Improved Size-Tunable Synthesis of Monodisperse Gold Nanorods through the Use of Aromatic Additives. ACS Nano 2012, 6, 28042817.

(26) Gómez-Graña, S.; Hubert, F.; Testard, F.; Guerrero-Martínez, A.; Grillo, I.; Liz-Marzán, L. M.; Spalla, O. Surfactant (bi)layers on gold nanorods. Langmuir 2012, 28, 1453-1459.

(27) Soliman, M. G.; Pelaz, B.; Parak, W. J.; del Pino, P. Phase Transfer and Polymer Coating Methods toward Improving the Stability of Metallic Nanoparticles for Biological Applications. Chem. Mater. 2015, 27, 990-997.

(28) del Pino, P.; Yang, F.; Pelaz, B.; Zhang, Q.; Kantner, K.; Hartmann, R.; Martinez de Baroja, N.; Gallego, M.; Möller, M.; Manshian, B. B.; Soenen, S. J.; Riedel, R.; Hampp, N.; Paraka, W. J. Basic Physicochemical Properties of Polyethylene Glycol Coated Gold Nanoparticles that Determine Their Interaction with Cells. Angew. Chem., Int. Ed. 2016, 55, 5483-5487.

(29) Pelaz, B.; del Pino, P.; Maffre, P.; Hartmann, R.; Gallego, M.; Rivera-Fernández, S.; Martínez de la Fuente, J.; Nienhaus, G. U.; Parak, W. J. Surface Functionalization of Nanoparticles with Polyethylene Glycol: Effects on Protein Adsorption and Cellular Uptake. ACS Nano 2015, 9, 6996-7008.

(30) Rosman, C.; Pierrat, S.; Henkel, A.; Tarantola, M.; Schneider, D.; Sunnick, E.; Janshoff, A.; Sönnichsen, C. A New Approach to Assess Gold Nanoparticle Uptake by Mammalian Cells: Combining Optical Dark-Field and Transmission Electron Microscopy. Small 2012, 8, 3683-3690.

(31) Smith, A. R.; Shenvi, S. V.; Widlansky, M.; Suh, J. H.; Hagen, T. $\mathrm{M}$. Lipoic acid as a pontential therapy for chronic diseases associated with oxidative stress. Curr. Med. Chem. 2004, 11, 1135-1146.

(32) Chadwick, S. J.; Salah, D.; Livesey, P. M.; Brust, M.; Volk, M. Singlet Oxygen Generation by Laser Irradiation of Gold Nanoparticles. J. Phys. Chem. C 2016, 120, 10647-10657.

(33) Guerrero-Martínez, A.; Barbosa, S.; Pastoriza-Santos, I.; LizMarzán, L. M. Nanostars shine bright for you. Colloidal synthesis, properties and applications of branched metallic nanoparticles. Curr. Top. Colloid Interface Sci. 2011, 16, 118-127.

(34) Espinosa, A.; Silva, A. K. A.; Sánchez-Iglesias, A.; Grzelczak, M.; Péchoux, C.; Desboeufs, K.; Liz-Marzán, L. M.; Wilhelm, C. Cancer Cell Internalization of Gold Nanostars Impacts Their Photothermal Efficiency In Vitro and In Vivo: Toward a Plasmonic Thermal Fingerprint in Tumoral Environment. Adv. Healthcare Mater. 2016, 5, $1040-1048$

(35) Ekici, O.; Harrison, R. K.; Durr, N. J.; Eversole, D. S.; Lee, M.; Ben-Yakar, A. Thermal analysis of gold nanorods heated with femtosecond laser pulses. J. Phys. D: Appl. Phys. 2008, 41, No. 185501. 